\title{
Kefir ve Sağlık
}

\author{
Özge KÖROĞLU ${ }^{1}$, Esra BAKIR ${ }^{1}$, Günsel ULUDAĞ ${ }^{1}$, Sedat KÖROĞLU ${ }^{2}$, Kenan Sinan DAYISOYLU ${ }^{1 *}$ \\ 1 KSÜ, Ziraat Fakültesi, Gıda Mühendisliği Bölümü, Kahramanmaraş \\ 2Necip Fazıl Şehir Hastanesi, Kardiyoloji Kliniği, Kahramanmaraş
}

Geliş (Received): 20.11.2014

Kabul (Accepted): 20.02.2015

\begin{abstract}
Özet: Son yıllarda toplumlar beslenme konusunda giderek daha bilinçli hale gelmektedir. Beslenme konusunda temel talep olan sağlıklı ve güvenli gıdalar tüketebilme isteğinin yanında; insan sağlığına ek faydalar sağlayan, hastalıklardan koruma potansiyeli olan ve fonksiyonel gida olarak adlandırılan ürünlere ulaşma isteği de giderek artmaktadır. Kefir, fonksiyonel gıdalardan probiyotikler alt kolunun önemli bir üyesi olup, içeriğinde birçok faydalı maya ve bakteri bulunduran, son y1llarda popülaritesi gittikçe artan fermente bir süt ürünüdür. Bu çalışmada, güncel bilgiler ışı̆̆ında kefirin metabolik faaliyetler ve sağlık yararları üzerinde durulmuştur.
\end{abstract}

Anahtar Kelimeler: Fonksiyonel gıda, kefir, insan sağlığı, probiyotikler

\section{Kefir and Health}

Abstract: In recent years, the societies became more conscious about the nutrition. Healthy and reliable food is the main demand, however, request to functional foods which can be briefly defined as beneficial nutrients to human health increases. Kefir is an important member of the probiotics, which are the subgroup of functional foods. It is a fermented milk product and contains useful bacteria and yeasts. In this text, the health and metabolism effects of the kefir are discussed in the light of current literature.

Key Words: Functional foods, human health, kefir, probiotics

\section{G R Ş}

Fonksiyonel gida, vücudun temel besin maddelerine olan ihtiyacını karşılamanın ötesinde insan fizyolojisi ve metabolik fonksiyonları üzerinde ek faydalar sağlayan, böylelikle hastalıklardan korunmada ve daha sağlıklı bir yaşama ulaşmada etkinlik gösteren gida veya gıda bileşenleridir (Karakaya, 2006; Messina ve ark., 2008; Hacioğlu ve Kurt, 2012; Bigliardi ve Galati, 2013). 'Fonksiyonel gıdalar arasında yer alan' sağlığa yararlı olduğu kanıtlanmış ve canlı mikroorganizmalar içeren ya da bunlar tarafından üretilen gidalar probiyotik olarak adlandırılır (Farnworth, 2006). Probiyotikler, yüzyıllardır insanlar tarafından geleneksel olarak farklı şekilde kullanılmaktadır. Son yıllarda giderek artan ve çeşitlenen çalışmalar, fermente süt ürünlerinin probiyotik etkileri üzerine yoğunlaşmaktadır. Bunlar arasında en çok ilgi çekenlerden birisi, kendine has probiyotik özellikli mikroorganizmaları içeren ve kompleks yapısı olan kefirdir. Kefir, kefir daneleri tarafından oluşturulan, Lactobacillus acidophilus, Bifidobacterium bifidum gibi doğal probiyotikler ile birçok laktik asit bakterisi ve maya içeren fermente bir süt ürünüdür (Güzel-Seydim ve ark., 2011). Türkçe 'keyif' kelimesinden türetilmiştir (Kurmann, 1984; Zhou ve ark., 2009). Kefir daneleri kü̧̈ük karnabahar veya mısır patlağı görünümlü, düzensiz şekilli, sarıbeyaz renkte elastik yapılardır. Polisakkarit bir yapı içinde bakteri ve mayaları içinde bulunduran simbiyotik bir fermente süt ürünü aracısıdır (Loretan ve ark., 2003; Plessas ve ark., 2007).

Güncel literatürde, kefirin, antikarsinojenik, bağışıklık sistemi düzenleyici, kolesterol düzenleyici, antialerjik, kan şekeri düzenleyici, antimikrobiyel, laktoz intoleransı azaltıcı, tansiyon düşürücü, sindirim sistemi üzerine etkileri çeşitli çalışmalarla kanıtlanmıştır (Güzel-Seydim ve ark., 2011; Maalouf ve ark., 2011; Adiloglu ve ark., 2013; Ahmed ve ark., 2013; De Angelis Pereira ve ark., 2013; De Oliveira Leite ve ark., 2013). Ancak kefir danesi çeşitliliğgi ve içeriğinin farklılığı literatürdeki bilimsel çalışmaları doğrudan kıyaslamayı zorlaştırmaktadır. Bu derlemede amaç, son yillarda tüketim eğilimi oldukça yüksek olan, işlevsel özelliğe sahip kefir ürünü üzerine yapılmış güncel bilimsel çalışmaları derlemek, böylece tüketici sağlığına ve bilincine katkı sağlamaktır.

\section{ANT KARS NOJEN K ETK}

Güzel-Seydim ve ark. tarafından farklı kimyasal mutajenler kullanılarak Ames Salmonella mikrozomal testinde süt, yoğurt ve kefirin antimutajenik aktiviteleri test edilmiştir. Fermente süt ürünleri olan yoğurt ve kefirin antimutajenik etkilerinin fermente edilmemiş süte göre daha yüksek olduğu gösterilmiştir (GüzelSeydim ve ark., 2006). çerdikleri bazı proteinlerin ve küçük peptidlerin bu etkide rolü olduğu ileri sürülmüştür. Kanser başlamasını yavaşlatma mekanizmalarından birisinin de bağışıklık sistemini aktive etmeleri olduğu gösterilmiştir (Kneating, 1985). Kefir ve kefir danesinin antikarsinojenik etkisi yaygın bir şekilde araştırılmıştır (Rizk ve ark., 2009; Grishina ve ark., 2011; Ghoneum ve ark., 2014; Khoury ve ark., 2014). Suda çözünebilen bir glukogalaktan olan, kefir daneleri ya da $L$. kefiranofaciens tarafından üretilen Kefiranin da tümör karşıtı aktivitesi gösterilmiş olup bu 
aktivitenin doz bağımlı olduğu ve suda çözünmeyen polisakkaritlere göre daha etkili olduğu kanıtlanmıştır (Murofishi ve ark., 1983; Furukawa ve ark., 2000). Polisakkaritlerin dozu ve doğasından farklı olarak tümör karşıtı etki aynı zamanda fermentasyonda etkili mikroorganizma özellikle Lactobacillus ve maya çeşidine de bağlıdır (Liu ve ark., 2002; Santos ve ark., 2003). Kefirin içerdiği proteinlerin de tümör karşıtı etkinliği gösterilmiştir. Özellikle sülfür içeren aminoasit grubunun kefir ve benzeri ürünlerin antikarsinojenik etkilerinde önemli pay sahibi olduğu öne sürülmüştür (Güzel-Seydim ve ark., 2003). Son dönemlerde araştırmacılar insanlarda bulunan tümörlerde kefir çalışmalarına hız vermiştir. Maalouf ve ark. (2011), kefirin HTLV-1 negatif malign T lenfositler üzerinde çoğalmayı önleyici ve programlanmış hücre ölümünü hızlandırıcı etkiler gösterdiğini kanıtlamışlardır. Ayrıca, Ghoneum ve Gimzewski (2014) çalışmalarında, Probiotics Fermentation Technology (PFT) kefir danesi ürününün çoklu ilaca dirençli miyeloid lösemide potansiyel bir tedavi alternatifi olabileceğini öne sürmüşlerdir. PFT, temel olarak Lactobacillus kefiri' nin özgün büyüme özelliklerine sahip spesifik bir danesi olan Lactobacillus kefiri P-IF içeren doğal bir karışımdır. Çalışmada, PFT'nin temel etkisinin kanser hücre duvarlarında delik oluşturarak apopitozisi etkinleştirmek olduğu tespit edilmiştir.

\section{BAĞIŞIKLIK S STEM ÜZER NE ETK LER}

Beslenme ve bağ $\breve{s ̧}_{1 k l 1 k}$ sistemi arasında doğrudan bir ilişki vardır (Vinderola ve ark, 2006a). Kefirin bağışıklık mekanizması üzerine düzenleyici etkisi olduğu gösterilmiştir (Zhou ve ark., 2009). Kefirin ağızdan uygulanması sonucunda, kolera hastalığını oluşturan vibrio cholerae bakterisinin ürettiği ve hastalığın patogenezinde temel rol oynayan kolera toksinine karşı genç farelerde özgül barsak mukozal bağışıklık yanıtını artırdığı tespit edilmiştir (Thoreux ve Schmucker, 2001). Vinderola ve ark. kefirin bağ 1 şıklık sistemi düzenleyici etkisini fare modeli üzerinde kanıtlamışlardır. Çalışmada, kefir uygulanması sonrası akciğer ve karın zarı makrofajlarının, patojenlerin aktivitelerini daha etkili şekilde azaltabileceği gösterilmiştir (Vinderola ve ark., 2005). Son dönemlerde az sayıda gönüllü insanlar üzerinde yapılan çalışmada altı haftalık kefir tüketimi sonucunda interlökin 8 düzeylerinde azalma, interlökin 5 ve TNF- $\alpha$ düzeylerinde artma saptanmıştır. Bu bulgular, vücutta yangının kontrol altına alınacağı, mide-barsak sisteminde de bağışıklık yanıtının daha etkili olacağ şeklinde yorumlanmıştır (Adiloğlu ve ark., 2013).

\section{KOLESTEROL DÜŞÜRÜCÜ ETK S}

Kolesterol yüksekliği olan farelerde kefir, VLDL, LDL, triasilgliserol seviyelerini anlamlı olarak düşürürken; HDL kolesterol seviyelerini yükseltmektedir. $\mathrm{Bu}$ sonuçlar kalp-damar hastalıklarından korunmak için tam da kolesterolde olması gereken değişikliklerdir. Kefirin yağ düşürücü etki mekanizması tam olarak bilinmese de; kefirdeki bakteri ve mayaların safra asidi parçalayıcı enzimler oluşturup kolesterol emilimini azaltarak ve kolesterol sentezinin en önemli enzimi olan HMG-CoA redüktazın aktivitesini düşürerek bu etkiyi sağlayabileceği öne sürülmektedir (De Angelis Pereira ve ark., 2013). Öne sürülen farklı mekanizmalardan birisi de, kefir fermentasyonu sirasinda orotik asitlerin azalmasidır (Özer ve Özer, 1999). Farklı bir çalışmada ise, kolesterolü düşük 13 erkekte yapılan çalışmada da kefir tüketiminin plazma yağ seviyesini etkilemediği tespit edilmiştir (St-Onge ve ark., 2002).

\section{ANT ALERJ K ETK LER}

Eozinofiller, alerjik reaksiyonlarda inflamasyon alanında yer alan ve alerjenle başlayan patolojik süreçte etkin rol oynayan bağışıklık sistemi elemanlarıdır. Bronşiyal astım, atopik dermatit gibi alerjik temeli olan hastalıklarda eozinofiller hem kanda hem de ilgili dokuda artmıştır. Eozinofil artışını ya da etkilerini azaltmak alerjik hastalıkların önlenme ve tedavisinde oldukça önemlidir (Yalçın, 2005). Kefirin akciğer dokusunda ovalbumin aracılı eozinofil artışını ve aşırı mukus salgılanmasını azalttığı gösterilmiştir (Lee ve ark, 2007). Bu, alerjik bronşiyal astımın tedavisinde ciddi bir umut vermektedir. Diğer bir çalışmada ise, kefiranin mast hücre degranülasyonunu baskıladığı ve bu nedenle mast hücre aracılı alerjik hastalıkların korunma ve önlenmesinde etkili olabileceği öne sürülmüştür (Furuno ve Nakanishi, 2012).

\section{KAN ŞEKER DÜZENLEY C ETK $S$}

Kefirin kan şekeri düzenleyici etkileri konusunda da dikkat çekici çalışmalar vardır. Kefiran-kefirin suda çözünen kısımlarının iskelet kası hücrelerinde glikoz alımını artırdığı ve bunun Tip 2 diyabet tedavisinde kullanılabileceği savunulmuştur. Araştırmacılar, etkin olan maddenin küçük moleküler yapıda olduğunu, pH ve 1s1 değişikliklerinden etkilenmediğini göstermişlerdir. Böylelikle kefiran-kefirin suda çözünen ve etkin olan kısmı ağızdan alındıktan sonra mide asidinde bozulmayacak ve küçük yapısı sayesinde barsaktan kolaylıkla emilecektir (Teruya ve ark., 2002).

\section{ANT M KROB YEL ETK LER}

Kefirin içerdiği laktobasil türlerinin antimikrobiyel bileşenler üretmeleri yanı sıra, fermentasyon sırasında mikrofloranın ortaya çıkardığı bazı metabolitler de etki etmektedir. Birincil ve ikincil metabolitler arasında küçük peptidler, diasetiller ve organik asitler sayılabilir (Golowczyc ve ark., 2008). Kefirin, Gram negatif bakteriler üzerinde bakteriyostatik; Gram pozitif bakteriler üzerinde ise bakterisitik etkisi daha ön planda olduğu belirtilmektedir (Czamanski ve ark., 2004). Kefirin bakterisitik etkisinin kanıtlandığ1 mikroorganizmalar: Listeria monocytogenes, Yersinia enterocolitica, Escherichia coli (Gülmez ve Güven, 
2003), Listeria innocua (Morgan ve ark., 2000), Salmonella enteritidis (Czamanski ve ark., 2004; Golowczyc ve ark., 2007), Staphylococcus aureus, Bacillus cereus, S. enteritidis, L. monocytogenes (ATCC 7644) ve E. coli (ATCC 8739) (Ulusoy ve ark., 2007)'dir. Kahverengi şekerde kültüre edilmiş kefirin Candida albicans, Salmonella Typhi, Shigella sonnei, S. aureus ve E. coli' yi inhibe ettiği gösterilmiştir (Silva ve ark., 2009). Pseudomonas aeruginosa ile enfekte cilt yanıklarında kefir jelinin geleneksel gümüş sulfadiazin tedavisine göre daha etkin olduğu gösterilmiştir (Huseini ve ark., 2012). Bu çalışmada, kefir daneleri (50 gram) 100 gram/litre MRS Broth besiyerine 24, 48, 96 saat sürelerle ekilmiştir. Kültür fermentasyonunun süpernatantı santrifüj edilmiş, filtre edilmiş ve 24-48-96 saatlik kefir olarak isimlendirilmiştir. Ardından 32 gram \%1 etil selüloz, 16 gram gliserin ve 52 gram propilen glikol karıştırılarak 100 gram baz jel oluşturulmuştur. Oluşturulan her 100 gram baz jele, daha önceden hazırlanan 24-48-96 saatlik kefirlerden 100 gram eklenerek 3 farklı kefir jeli elde edilmiştir. Çalışma sonucunda 96 saatlik kefir jelinin yara iyileşmesinde diğerlerine kıyasla daha etkili olduğu kanıtlanmıştır.

\section{LAKTOZ NTOLERANSINI AZALTICI ETK S}

Laktoz, tüm memeli sütlerinde bulunan temel disakkarittir ve laktoz sindirim bozukluğu barsakta yetersiz $\beta$-galaktosidaz olması sebebiyle oldukça yaygındır (Alm, 1982). Kefir danelerinde bulunan $\beta$ galaktosidaz, hidroliz yoluyla laktoz içeriğini azaltır ve laktoz intoleransı olan bireylerde laktoz içeren ürünlerin tüketimini kolaylaştırır (De Vrese ve ark., 1992). Laktoz intoleransı olan kişilerde ağı kokusu tedavisinde de kefir yoğurt kadar etkilidir (Hertzler ve Clancy, 2003). Daha düşük laktoz içeriği ve daha yüksek $\beta$ galaktozidaz aktivitesi nedeniyle kefirin laktoz tolerans bozukluğu olan bireylerde laktoz sindirimini kolaylaştırdığı ve şişkinlik hissini \%71'lere varan oranlarda azalttığı bildirilmiştir (De Vrese ve ark., 1992; Hertzler ve Clancy, 2003).

\section{KAN BASINCI ÜZER NE ETK LER}

Kefiranın farelerde kan basıncını anlamlı ölçüde düşürdüğü gösterilmiştir (Maeda ve ark., 2004). Kan basıncındaki düşüş, kan basıncı düzenlenmesinde önemli etkisi olan anjiyotensin dönüştürücü enzim etkisinin baskılanmasına bağlı olabilir. Anjiyotensin dönüştürücü enzim baskılayıcıları günümüzde hipertansiyon tedavisinde kullanılan en önemli ilaçlar arasında yer almaktadır. Kefirin içerdiği on altı proteinin ikisinin anjiyotensin dönüştürücü enzim baskılayıcı etki gösterdiği kanıtlanmıştır (Quiros ve ark., 2005).

\section{S ND R M S STEM ÜZER NE ETK LER}

Süt, peynir ve tereyağının tersine kefir, sindirim sisteminin motor ve boşalma işlevi üzerine uyarıcı etkiye sahiptir (Loranskala ve ark., 1986). Kefir, antagonistik etkisiyle barsakta patojen bakteri kolonizasyonunu engellemektedir (Zacconi ve ark., 2003). Kefir, Rusya'da araştırmacılar tarafından insanlarda mide ve on iki parmak barsak ülserleri tedavisinde kullanılmaktadır (Farnworth ve Mainville, 2008).

\section{SONUÇ}

Kefir, probiyotik özellikli bakterileri içermesi ve sağlık açısından yararları gün geçtikçe kanıtlanmasıyla sebebiyle tüketici tercihinde giderek daha fazla kullanılmaya başlanmış, gıda endüstrisinde önemli bir konum edinmiştir. Her ne kadar sonuçları henüz bilimsel açıdan istenilen düzeyde olmasa da; hakkında yapılan onlarca çalışmada, bu geleneksel içeceğin insan sağlığı üzerine olumlu etkiler sağlayabileceği konusunda araştırmacılar hemfikirdir. Yapılan çalışmalarda, denek hayvanları yerine gönüllü insanlardan oluşan farklı denek gruplarının kullanılması, kullanılan kefir içeriğinin standartlaştırılması, kontrol gruplarının uygun seçilmesi ve daha geniş örneklem gruplarının dâhil edilmesi, bu umut vadeden ürünün geleceğini belirlemede önemli gerekliliklerdendir.

\section{KAYNAKLAR}

Adiloğlu, A.K., Gönülateş, N., şler, M., Şenol, A. 2013. Kefir tüketiminin insan bağışıklık sistemi üzerine etkileri: Bir sitokin çalışması. Mikrobiyoloji Bülteni, 47(2): 273-281.

Ahmed, Z., Wang, Y., Ahmad, A., Khan, S.T., Nisa, M., Ahmad, H., Afreen, A. 2013. Kefir and Health: A Contemporary Perspective. Critical Reviews in Food Science and Nutrition, 53(5): 422-434.

Alm, L. 1982. Effect of fermentation on lactose, glucose, and galactose content in milk and suitably of fermented milk products for lactose intolerant individuals. Journal of Dairy Science, 65(3): 346352 .

Bigliardi, B., Galati, F. 2013. Innovation trends in the food industry: The case of functional foods. Trends in Food Science \& Technology, 31(2): 118-129.

Czamanski, R.T., Greco, D.P., Wiest, J.M. 2004. Evaluation of antibiotic activity in filtrates of traditional kefir. Higiene Alimentar, 18 (124): 75-77.

De Angelis-Pereira, M.C., Barcelos, M.F.P., Sousa, M.S.B., Pereira, J.A.R. 2013. Effects of the kefir and banana pulp and skin flours on hypercholesterolemic rats. Acta Cirurgica Brasileira, 28(7): 481-486.

De Oliveira Leite, A.M., Miguel, M.A., Peixoto, R.S., Rosado, A.S., Silva, J.T., Paschoalin, V.M. 2013. Microbiological, technological and therapeutic properties of kefir: a natural probiotic beverage. Brazilian Journal of Microbiology, 44(2): 341-349.

De Vrese, M., Keller, B., Barth, C.A. 1992. Enhancement of intestinal hydrolysis of lactose by microbial $\beta$-galactosidase (EC 3.2.1.23) of kefir. British Journal of Nutrition, 67(1): 67-75. 
Farnworth, E.R. 2006. Probiotics and Prebiotics. (Nutraceuticals and Functional Foods, (2. ed) CRC Press, Taylor\&Francis Group, Boca Raton, London, New York: Ed. Wildmann R.E.C.) 335.

Farnworth, E.R., Mainville, I. 2008. Kefir-A Fermented Milk Product. (Handbook of Fermented Functional Foods (2. ed) CRC Press, Taylor\&Francis Group, Boca Raton, London, New York: Ed. Farnworth E.R.) 89-127.

Furukawa, N., Matsuoka, A., Takahashi, T., Yamanaka, Y. 2000. Antimetastatic effect of Kefir grain components on Lewis lung carcinoma and highly metastatic B16 melanoma in mice. Journal of Agricultural Science, 45(1): 62-70.

Furuno, T., Nakanishi, M. 2012. Kefiran suppresses antigen-induced mast cell activation. Biological and Pharmaceutical Bulletin, 35(2): 178-183.

Ghoneum, M., Gimzewski, J. 2014. Apoptotic effect of a novel kefir product, PFT, on multidrug-resistant myeloid leukemia cells via a hole-piercing mechanism. International Journal of Oncology, 44(3): 830-837.

Golowczyc, M. A., Mobili, P., Garrote, G. L., Abraham, A. G., De Antoni, G. L. 2007. Protective action of Lactobacillus kefir carrying S-layer protein against Salmonella enterica serovar Enteritidis. International Journal of Food Microbiology, 118(3): 264-273.

Golowczyc, M.A., Gugliada, M.J., Hollmann, A., Delfederico, L., Garrote, G.L., Abraham, A.G., Semorile, L., De Antonie, G. 2008. Characterization of homofermentative lactobacilli isolated from kefir grains: Potential use as probiotic . Journal of Dairy Research, 75(2): 211-217.

Grishina, A., Kulikova, I., Alieva, L., Dodson, A., Rowland, I., Jin, J. 2011. Antigenotoxic effect of kefir and ayran supernatants on fecal water-induced DNA damage in human colon cells. Nutrition and Cancer, 63(1): 73-79.

Gülmez, M., Güven, A. 2003. Behavior of Escherichia coli 0157: H7, Listeria monocytogenes $4 \mathrm{~b}$ and Yersenia enterocolitica 03 in pasteurized and nonpasteurized Kefir fermented for one or two days. Food Science and Technology International, October 9: 365-369.

Güzel-Seydim, Z.B., Seydim, A.C., Greene, A.K. 2003. Comparison of amino acid profiles of milk, yogurt and Turkish Kefir. Milchwissenschaft, 58(3-4): 158160.

Güzel-Seydim, Z.B., Seydim, A.C., Greene, A.K., Taş, T. 2006. Determination of antimutagenic properties of some fermented milks including changes in the total fatty acid profiles including conjugated linoleic acids. International Journal of Dairy Technology, 59(3): 209-215.

Güzel-Seydim, Z.B., Kok-Tas, T., Greene, A.K., Seydim, A.C. 2011. Review: Functional properties of Kefir. Critical Reviews in Food Science and Nutrition, 51(3):261-268.
Hacioğlu, G., Kurt, G. 2012. Tüketicilerin Fonksiyonel Gıdalara Yönelik Farkındalığı, Kabulü ve Tutumları: zmir li Örneği. Business and Economics Research Journal, 3(1): 161-171.

Hertzler, S.R., Clancy, S.M. 2003. Kefir improves lactose digestion and tolerance in adults with lactose maldigestion. Journal of the American Dietetic Association, 103(5): 582-587.

Huseini, H.F., Rahimzadeh, G., Fazeli, M.R., Mehrazma, M., Salehi, M. 2012. Evaluation of wound healing activities of kefir products. Burns, 38(5): 719-723.

Karakaya, S. 2006. Fonksiyonel Gidalar ve Destekler. http:/food.ege.edu.tr/files/fonksiyonelgidalarvedeste kler.ppt. (Erişim tarihi: 15.11.2014).

Khoury, N., El-Hayek, S., Tarras, O., El-Sabban, M., El-Sibai, M., Rizk, S. 2014. Kefir exhibits anti-proliferative and pro-apoptotic effects on colon adenocarcinoma cells with no significant effects on cell migration and invasion. International Journal of Oncology, 45(5): 2117-2127.

Kneating, K. 1985. The role of cultured dairy products in the prevention of stomach cancer. Cultured Dairy Products Journal, 20: 13-14.

Kurmann, J. 1984. Fermented milks. BulletinInternational Dairy Federation, 179: 16-26.

Lee, M.Y., Ahn, K.S., Kwon, O.K., Kim, M.J., Kim, M.K., Lee, I.Y., Oh, S.R., Lee, H.K. 2007. Antiinflammatory and anti-allergic effects of kefir in a mouse asthma model. Immunobiology, 212(8): 647654.

Liu, J.R., Wang, S.Y., Lin, Y.Y., Lin, C.W. 2002. Antitumor activity of milk kefir and soy milk kefir in tumor-bearing mice. Nutrition and Cancer, 44(2): 183-187.

Loranskala, T.I., Khoromskii, L.N., Benedikt, V.V. 1986. Effects of a series of food substances on motor and emptying function of the gastric stump and diverting intestinal loop after stomach resection and truncal vagotomy. Voprosy Pitaniia, 1: 19-22.

Loretan, T., Mostert, J.F., Viljoen, B.C. 2003. Microbial flora associated with South African household kefir: research letter. South African Journal of Science, 99(1\&2): 92-94.

Maalouf, K., Baydoun, E., Rizk, S. 2011. Kefir induces cell-cycle arrest and apoptosis in HTLV-1-negative malignant T-lymphocytes. Cancer Managemet and Research, 3: 39-47.

Maeda, H., Zhu, X., Omura, K., Suzuki, S., Kitamura, S. 2004. Effects of an exopolysaccharide (kefiran) on lipids, blood pressure, blood glucose, and constipation. Biofactors, 22(1): 197-200.

Messina, F., Saba, A., Turrini, A., Raats, M., Lumbers, M. 2008. Older people's perceptions towards conventional and functional yoghurts through the repertory grid method: A cross-country study. British Food Journal, 110(8): 790-804. 
Morgan, S. M., Hickey, R., Ross, R. P., and Hill, C. 2000. Efficient method for the detection of microbially-produced antibacterial substances from food systems. Journal of Applied Microbiology, 89(1): 56-62.

Murofushi, M., Shiomi, M., Aibara, K. 1983. Effect of orally administered polysaccharide from kefir grain on delayed-type hypersensitivity and tumor growth in mice. Japanese Journal of Medical Science \& Biology, 36(1): 49-53.

Özer, D., Özer, B. 1999. Product of Eastern Europe and Asia. (Encyclopedia of Food Microbiology, Academic Press, London: Ed. Robinson R.) 798805.

Plessas, S., Trantallidi, M., Bekatorou, A., Kanellaki, M., Nigam, P., Koutinas, A.A. 2007. Immobilization of kefir and Lactobacillus casei on brewery spent grains for use in sourdough wheat bread making. Food Chemistry, 105(1): 187-194.

Quiros, A., Hernandez-Ledesma, B., Ramos, M., Amigo, L., Recio, I. 2005. Angiotensinconverting enzyme inhibitory activity of peptides derived from caprine kefir. Journal of Dairy Science, 88(10): 3480-3487.

Rizk, S., Maalouf, K., Baydoun, E. 2009. The antiproliferative effect of kefir cell-free fraction on HuT-102 malignant $\mathrm{T}$ lymphocytes. Clinical Lymphoma, Myeloma and Leukemia, 9(3): 198203.

Santos, A., San Mauro, N., Sanchez, A., Torres, J.M., Marquina, D. 2003. The antimicrobial properties of different strains of Lactobacillus spp. isolated from kefir. Systematic and Applied Microbiology, 26(3): 434-437.

Silva, K.R., Rodrigues, S.A., Filho, L.X., Lima, A.S. 2009. Antimicrobial activity of broth fermented with kefir grains. Applied Biochemistry and Biotechnology, 152(2): 316-325.
St-Onge, M.P., Farnworth, E.R., Savard, T., Chabot, D., Mafu, A., Jones, P.J. 2002. Kefir consumption does not alter plasma lipid levels or cholesterol fractional synthesis rates relative to milk in hyperlipidemic men: a randomized controlled trial. BMC Complementary and Alternative Medicine, 2(1): 1.

Teruya, K., Yamashita, M., Tominaga, R., Nagira, T., Shim, S.Y., Katakura, Y., Tokumaru S., Tokumaru, K., Barnes, D., Shirahata, S. 2002. Fermented milk, Kefram-Kefir enhances glucose uptake into insulinresponsive muscle cells. Cytotechnology, 40(1-3): 107-116.

Thoreux, K., Schmucker, D.L. 2001. Kefir milk enhances intestinal immunity in young but not old rats. The Journal of Nutrition, 131(3): 807-812.

Ulusoy, B. H., Çolak, H., Hampikyan, H., Erkan, M. E. 2007. An in vitro study on the antibacterial effect of kefir against some food-borne pathogens. Türk Mikrobiyoloji Cemiyeti Dergisi, 37:103-107.

Vinderola, G., Duarte, J., Thangavel, D., Perdigon, G., Farnworth, E., Matar, C., 2005. Remote-site stimulation and duration of the immune response by kefir. European Journal of Inflammation, 3: 63.

Vinderola, G., Perdigon, G., Duarte, J., Thangavel, D., Farnworth, E., Matar, C. 2006. Effects of kefir fractions on innate immunity. Immunobiology, 211(3): 149-156.

Yalçın, B. 2005. Allerjik Reaksiyonların Patogenezi: THücreleri ve Eozinofillerin Rolü. ç Hastalıkları Dergisi, 12(4): 209-214.

Zacconi, C., Scolari, G., Vescovo, M., Sarra, P.G. 2003. Competitive exclusion of Campylobacter jejuni by kefir fermented milk. Annals of Microbiology, 53(2): 179-188.

Zhou, J., Liu, X., Jiang, H., Dong, M. 2009. Analysis of the microflora in Tibetan kefir grains using denaturing gradient gel electrophoresis. Food Microbiology, 26(8): 770-775. 